\title{
Nueva presentación de Acta Médica Colombiana
}

\section{Acta Medica Colombiana new format}

\author{
Eugenio MatiJaseVic-Arcila • Bogotá, D.C. (Colombia)
}

\begin{abstract}
A partir de la invención de la escritura los materiales mediante los cuales almacenamos y transmitimos la palabra escrita han venido evolucionando de manera continua. Desde las tabletas de piedra Sumerias hasta las tabletas digitales actuales, los seres humanos hemos utilizado además como soporte material de la escritura, tablillas de arcilla en Mesopotamia y Micenas, láminas de madera (en especial de bambú) en la China de la Dinastía Shang, papiro en el antiguo Egipto, laminillas de metales (plomo y bronce principalmente) en la Grecia clásica, tablillas cubiertas de cera en Atenas y Roma, pergamino en la Grecia Helenística, seda y papel en la China de la Dinastía Han.

Cada uno de estos materiales de soporte de la escritura ha tenido un proceso de desarrollo y expansión que puede seguirse a lo largo de la historia (de hecho la historia comienza con ellos: antes de la aparición de la escritura no hay historia, sólo prehistoria), pero ninguno de esos materiales ha sido de uso exclusivo de las civilizaciones que los crearon, ni de la época en que fueron creados; el papiro, para citar sólo un ejemplo, comenzó a utilizarse en el antiguo Egipto al menos desde el siglo XXV AEC, se difundió a las culturas griega y romana clásicas y continuó en uso hasta bien avanzada la edad media (1).
\end{abstract}

Si bien es cierto que el papel era hasta hace muy poco el medio más utilizado para almacenar, transportar y leer el lenguaje escrito, seguimos escribiendo en piedra (monumentos, estelas, lápidas), en pergamino (diplomas, leyes de honores), en papiro y seda (textos ornamentales), en láminas metálicas (trofeos deportivos, placas conmemorativas). Sin duda, cada vez utilizamos menos dichos soportes materiales de la escritura, pero los utilizamos con propósitos específicos en los que resulta claro que tienen ventajas sobre otros soportes (¿imagina el lector un epitafio de papel, o el monumento a la independencia en una pantalla de cristal líquido?).

En las últimas décadas, el desarrollo de la computación electrónica y de las comunicaciones ha prohijado el surgimiento de nuevos soportes de la escritura, cuya exteriorización frente a los lectores es una interfaz usuario-ordenador formada por una pantalla de cristal líquido (que dejó obsoleta a la de rayos catódicos) respaldada por programas de procesamiento de textos, celdas de almacenamiento, canales de comunicación, unidades aritmético-lógicas, registros de coma flotante y unidades centrales de procesamiento que permiten la creación, el procesamiento, la conservación, el depósito y el intercambio de textos. Esto último gracias a la interconexión de innumerables computadores personales y servidores de acceso público en todo el orbe mediante redes de comunicación, entre las cuales la red de redes, Internet, permite la intercomunicación entre ordenadores de subredes diversas (privadas, académicas, estatales).

Dicha red digital, con sus terminales, ha venido desplazando al papel como soporte de la escritura y como método de intercambio de información textual, aunque no sobra agregar que también está desplazando otros medios de comunicación y de entretenimiento (y muchos canales de negocios), no sólo escritos sino sonoros y de imágenes en movimiento, y que en la actualidad el correo postal, los diarios de noticias, los semanarios, la telegrafía, la radiofonía, la difusión de música, la televisión, la difusión cinematográfica y hasta los juegos se están volcando hacia este nuevo formato gracias a su versatilidad.

En el campo de los libros este proceso aún no es completo y quizás el cambio del formato de papel al libro electrónico o libro digital no se dé tan rápido como muchos vaticinan. De hecho, son muchas las voces que consideran dicho cambio superfluo y se
Dr. Eugenio Matijasevic-Arcila: Editor General Acta Médica Colombiana. Bogotá, D. C. (Colombia).

E-mail: eugenio.matijasevic@gmail.com Recibido: 22/VII//2019 Aceptado:23/VII/2019 
alzan en defensa del libro de papel y sus ventajas abogando porque éste no desaparezca $(2,3)$. Pero en el campo de las publicaciones científicas periódicas la situación es de otro tenor: el cambio al formato digital ya se dio y el desplazamiento ha sido prácticamente completo.

El objetivo de las publicaciones científicas periódicas ha sido y será siempre enlazar la producción del conocimiento con la comunidad de científicos que lo generan, en un círculo virtuoso en el que la difusión del conocimiento producido abre la posibilidad de que dicho conocimiento sea recogido por otros investigadores que trabajan en el mismo campo o en campos afines y sirva entre ellos de simiente para nuevas investigaciones que darán lugar a una mayor producción de conocimiento que, a su vez, requerirá difusión que, de nuevo, incrementará la producción de conocimiento.

En este sistema de retroalimentación positiva las ventajas del formato electrónico o digital son indudables, tanto desde el punto de vista de la difusión del conocimiento como de la producción del mismo, es decir, tanto para los lectores como para los investigadores: el informe de un trabajo de investigación puede ser desarrollado, corregido y almacenado en un computador personal y enviado en línea a la publicación científica periódica para su posible difusión (en esta fase, antes de su publicación, sigue llamándose "el manuscrito" aunque ya no sea escrito a mano ni sobre el papel, sino mediante un programa de procesamiento de textos); el trabajo publicado no tiene límite en el número de páginas; es posible publicar en la red material complementario para explicar, reforzar o defender los hallazgos del trabajo de investigación; la revisión por pares es mucho más rápida; el proceso de producción también es más rápido; los costos del proceso de publicación son mucho menores en la medida en que no se utiliza papel, ni tinta, ni impresoras; el proceso de distribución a los lectores es también más sencillo y menos costoso, basta un clic para que todos los subscriptores reciban la revista en sus computadores personales; la búsqueda del artículo publicado por parte de los lectores, o de artículos similares, se facilita igualmente mediante la búsqueda en bases de datos especializadas o globales y la posibilidad de que un artículo relevante para un tema específico sea citado se multiplica (4).

Obviamente esto implica nuevos retos. Se requiere una base material física en donde se guarden los archivos (la nube no existe, es simplemente un nombre para no admitir que nuestros datos están en un servidor que no nos pertenece) (5), así que en algún lado debe existir un soporte magnético o unos discos ópticos en donde se guarden los archivos de la revista o pagar para que alguien los guarde y responda por ellos y sea posible recuperarlos en caso de que se caiga la red o desaparezca la nube o alguien robe los datos o los secuestre a cambio de una recompensa o cualquier eventualidad por el estilo, como ha ocurrido (6). Es necesario identificar cada artículo publicado con el fin de poder hacerle seguimiento en la red, de ello se encarga el Digital Object Identifier (DOI) (7); también es necesario identificar a los autores aunque cambien de nombre o apellidos o aunque los deletreen de manera diferente, con el fin de establecer qué han publicado, cuándo, dónde, de ello se encarga el Open Researcher and Contributor ID (8) (ORCID); se necesitan estadísticas fiables para cada artículo publicado y para cada autor y para cada revista con parámetros reales de lectura y descarga, como las ofrecidas por Altmetric (9), ImpactStory (10) o Plum Analytics (11).

El Comité Editorial de Acta Médica Colombiana, después de analizar la situación de la revista en el contexto colombiano y global, y con el fin de estar al día con los cambios que han venido ocurriendo a nivel mundial en todas las publicaciones científicas periódicas como consecuencia del advenimiento de la era digital, ha tomado la decisión de realizar importantes cambios en el formato de nuestra revista que comenzarán a implementarse a partir del próximo número.

En primer lugar, a partir del próximo número Acta Médica Colombiana abandonará el papel como soporte material de su publicación y se transformará en una publicación científica periódica completamente digital. Mantendremos los artículos en Portable Document Format (PDF), pero simultáneamente todos los artículos estarán en HyperText Markup Language (HTML), el lenguaje más utilizado en las páginas de la red, dada su versatilidad y la posibilidad de encontrarlos en las bases de datos mediante los algoritmos de búsqueda de plataformas como Google a partir de búsquedas con cualquier conjunto de las palabras que incluyan.

Además de su impacto positivo sobre el medio ambiente (la producción de papel genera efectos deletéreos ambientales tanto en sus fuentes como en sus desechos) (12), el abandono de la edición en papel permitirá un ahorro muy importante en los costos de producción de la revista. Dicho ahorro será utilizado, de acuerdo con las directrices del Comité Editorial, avaladas por la Junta Directiva de la Asociación Colombiana de Medicina Interna, propietaria de la revista, en la transformación completa de ésta en una revista bilingüe inglés-español. Las ventajas del bilingüismo en las publicaciones científicas periódicas son indudables: mayor visibilización de la revista, internacionalización de su contenido y de sus colaboradores, incremento en el número y pertinencia de las citaciones, mejoría en los niveles de indexación y catalogación en bases de datos y directorios.

Dicho ahorro en los costos de producción se utilizará, además, para contratar un programa anti-plagio, para cubrir los gastos del DOI de cada artículo, para hacer arreglos con un sitio en la red para preservación de copias de respaldo (LOCKSS o CLOCKSS o Portico) y adoptar una política de registro en depósito con Sherpa/RoMEO u otros repositorios de auto-archivo para publicaciones de acceso abierto.

Gracias al cambio a formato digital la revista podrá pasar al modo de edición continua: seguirá apareciendo el formato de páginas y números y volúmenes de la revista pero al mismo tiempo, dado que cada artículo irá identificado por su DOI, los artículos se publicarán de inmediato una vez se haya completado el proceso de evaluación por pares 
y de revisión editorial sin tener que esperar a completar un número. El sistema de publicación y manejo que en la actualidad utiliza nuestra revista, Open Journal Systems (OJS), se ha actualizado ya a su versión más reciente como parte de estos cambios.

Además, con el fin de ingresar por derecho propio a las revistas de acceso abierto (open access) y visibilizar la revista en el Directory of Open Access Journals (DOAJ) (13) a partir de la fecha los derechos de autor de cada artículo (copyright) quedarán en manos de los autores y no será necesario transferirlos a Acta Médica Colombiana mediante la acostumbrada página "Documento modelo para garantías y cesión de derechos de copia a favor de Acta Médica Colombiana". Igualmente cada artículo aparecerá con una licencia de Creative Commons que permita la redistribución no comercial del artículo, siempre y cuando éste circule íntegro y sin cambios, dando crédito a los autores (14).

\section{Referencias}

1 Gabrial B. History of Writing Technologies. In: Bazerman Ch (Ed): Handbook of Research on Writing, History, Society, School, Individual, Text. Londres: Routledge; 2007: pp 27-39.
2 Eco U, Carriere J-C. Nadie acabará con los libros. Barcelona: Lumen; 2010: $263 \mathrm{pp}$.

3 Meunier B. Le livre va-t-il disparaître face au monde de l'Internet ? In: Salon Du Livre, Montmorillon [Internet]. Montmorillon: Institut de France Académie des Sciences; 2014 [cited 2019 Jul 20]. p. 1-8. Available from: https://www. academie-sciences.fr/pdf/discours/s210614_meunier.pdf

4 Shotton D. Semantic publishing: The coming revolution in Scientific journal publishing. Learn Publ 2009;22(2):85-94.

5 Miller KW, Voas J. Ethics and the Cloud. IT Prof [Internet]. 2010 Sep [cited 2019 Jul 19];12(5):4-5. Available from: http://ieeexplore.iee.org/document/5593031/

6 Blumenthal MS. Is Security Lost in the Clouds?. Commun Strateg 2011; 81(1): 69-86.

7 Paskin N. Toward unique identifiers. Proc IEEE [Internet]. 1999 Jul [cited 2019 Jul 19];87(7):1208-27. Available from: http://ieeexplore.iee.org/document/771073/

8 ORCID [Internet]. [cited 2019 Jul 19]. Available from: https://orcid.org/

9 Altmetric [Internet]. [cited 2019 Jul 19]. Available from: https://www.altmetric. com/

10 Our Research [Internet]. [cited 2019 Jul 22]. Available from: https://our-research. org/

11 Plum Analytics [Internet]. [cited 2019 Jul 22]. Available from: https://plumanalytics.com/

12 Hershkowitz A. Bronx ecology: Blueprint for a New Environmentalism. Washington DC: Island Press; 2002: p. 62.

13 Directory of Open Access Journals [Internet]. [cited 2019 Jul 22]. Available from: https://doaj.org/

14 Licencias I Creative Commons Colombia [Internet]. [cited 2019 Jul 22]. Available from: https://co.creativecommons.org/?page_id=13 